\title{
Eles eram muitos cavalos: leituras. Breves considerações estéticas e políticas
}

\author{
Fabiana Carneiro da Silva ${ }^{1}$
}

RESUMO: Este trabalho propõe-se a fazer uma reflexão acerca do modo com que o romance Eles eram muitos Cavalos (2001), de Luiz Ruffato, graças aos seus procedimentos estéticos, dispõe-se como objeto para as mais diversas leituras críticas. Para isso, nos deteremos numa análise comparativa de dois ensaios sobre a obra, presentes na coletânea Uma cidade em Camadas (2007). Procuraremos situar a obra e os ensaios em seu contexto histórico e explicitar algumas das implicações políticas inerentes à escolha dos critérios de valoração estética deles.

ABSTRACT: This paper proposes a reflexion on how the romance Eles eram muito Cavalos (2001), by Luiz Ruffato, due to his aesthetical procedures, becomes an object to various critical readings. We will detain ourselves to a comparative analysis of two essays on this work, found in the compilation Uma cidade em Camadas (2007). We will attempt to situate the work and the essays on their historical context and explicit some of the political implications inherent to the choice of the criteria for their aesthetical values.

PALAVRAS-CHAVES: Eles eram muito cavalos; Desconstrução; Materialismo Dialético; Estética.

KEYWORDS: Eles eram muitos cavalos, Deconstruction, Dialectic materialism, Aesthetic.

\section{Da obra:}

Eles eram muitos cavalos (EEMC) foi publicado em 2001 e de imediato impôs alguns desafios à crítica encarregada de sua recepção. A falta de unidade no foco narrativo e na estrutura do livro - que é

1 Mestranda pelo departamento de Teoria Literária e Literatura Comparada da USP. Título da dissertação, em desenvolvimento: "A crise contemporânea do valor: um estudo de paradigmas de valoração estética na crítica literária”. Contato: fabicarneirodasilva@yahoo.com.br. 
composta por fragmentos intitulados, acabados em si mesmos, dispostos de modo não linear e sem relação alguma de causalidade - foi entendida como um fator problemático na concepção do livro como um romance. No entanto, uma leitura mais atenta justificou tal classificação, na medida em que permitiu constatar uma certa unidade composicional na obra, que teria como espaço e personagem principal a cidade de São Paulo, como enredo as diversas micro-histórias dos sujeitos que constituem essa cidade e a dimensão temporal de um dia (demarcado pelo cabeçalho presente no primeiro fragmento e pelas duas páginas negras, a noite/fim do dia, do fragmento 69)2 ${ }^{2}$.

Observamos, na economia interna ao romance, uma dinâmica de ruptura e continuidade com procedimentos e preocupações que caracterizaram a tradição moderna da produção literária. Desse modo, EEMC condensa duas vertentes identificadas por parte da critica literária como significativas na literatura contemporânea, uma ligada ao realismo e outra às vanguardas e aos experimentalismos. Desta última vertente, por exemplo, constatamos a incorporação de procedimentos como o uso de flashes, intertextos, a fragmentação, a não linearidade, a diversidade registros, a mescla de tempos e vozes numa mesma frase, a oralidade e a ausência de pontuação e mediações.

Por outro lado, vinculado ao realismo, está o descritivismo (às vezes de tom naturalista) e a notória objetividade da obra, na qual o narrador - ou os narradores - apresentam-se aparentemente sem subjetividade numa ânsia de apreender a sociedade a partir de uma certa particularização de seus indivíduos que se contrapõe, e também evidencia, à massificação deles a epígrafe da Cecília Meireles explicita tal motivação: "Eles eram muitos cavalos, mas ninguém mais sabe seus nomes, sua pelagem sua origem...”. O foco narrativo mantém-se colado às ações e aos personagens e não raro o narrador, nos diversos fragmentos, incorpora léxico, sintaxe, etc. do meio narrado.

2 A classificação da obra como romance, no entanto, permanece passivel de problematização. 
Nesse sentido, o modo como a matéria é narrada em EEMC também flerta com os procedimentos clássicos dos romances realistas de Balzac, Zola e Flaubert, ratificando alguns dos fundamentos do realismo moderno indicados por Auerbach, tais como:

o tratamento sério da realidade cotidiana, a ascensão de camadas humanas mais largas e socialmente inferiores à oposição de objetos de representação problemático-existencial e o engarçamento de personagens e acontecimentos cotidianos quaisquer no decurso geral da história contemporânea, do pano de fundo historicamente agitado. (1971, p.395-430)

Nesta obra, no entanto, o pano de fundo histórico é, como veremos, bem distinto daquele presente nos romances europeus do século XIX; em sua totalidade, ela expressa com agudez as condições e contradições do século XXI.

Pensando na experiência urbana presente na literatura brasileira deste século, Flora Süssekind (2005) sugere um novo padrão das diferenças sociais no espaço urbano, o qual expressaria a contradição pós-ditatorial entre a expansão da cidadania politica e a deslegitimação da cidadania civil. Essa sugestão é significativamente conceituada e desenvolvida por Francisco Oliveira (2007) que, em publicação recente, a partir da metáfora schwarziana do "desmanche", assinala uma série de fatores que teriam contribuído para a "destituição das possibilidades de democratização e republicanização anteriormente abertas pelo fim da ditadura militar". Segundo ele (p. 38), o sistema capitalista encontra-se num estágio em que a autonomização da esfera financeira alterou as formas de trabalho, dos espaços públicos, da cultura e sobretudo da política, criando uma nova e indeterminada sociabilidade ("a relação entre classe, interesse e representação foi para o espaço").

No Brasil, medidas tomadas principalmente durante o governo de Fernando Henrique Cardoso teriam reconfigurado a relação burguesia-estado, tornando este "refém do novo poder econômico centrado nas multinacionais produtivas e financeiras". Como consequência, observamos o aumento dos cinturões de pobreza, das 
desigualdades sociais, do desemprego, do narcotráfico e do crime organizado que, nas periferias das grandes cidades, tem como modelo, de acordo com o autor, a própria estrutura organizacional do capital financeiro. No plano global, estas transformações correspondem ao período histórico que é entendido por alguns teóricos como pósmodernidade, isto é, ao referido estágio em que o capital por um lado, teria tornado-se "volátil" (transnacional), impossibilitando a localização de sua origem e o controle de sua circulação e, simultaneamente, por outro, teria se expandido de tal modo que a reificação teria atingido praticamente todos os niveis da vida.

No que confere à literatura, vislumbramos um processo de generalização da estética que se difere do esteticismo do século XIX e da tentativa de estetização da vida promovida pelas vanguardas do início do século XX. Tal processo executa uma desestetização do campo interior ao que é definido como arte e de estetização do campo que é exterior, a qual explicita um constante deslizamento de valores e coloca em cena problemáticas como o fim da relativa autonomia do campo artístico, a "espetaculização" da política, a venda/consumo de estilos de vida, a centralidade da imagem e outros fenômenos que evidenciam a utilização da forma estética como mercadoria.

As histórias presentes em EEMC formalizam tal panorama, do desemprego (por exemplo, fragmento 18 e 19), da violência (fragmento 11), da pobreza (fragmento 9), do culto à imagem (fragmento 15), da exclusão e marginalidade (fragmento 34), da subordinação (fragmento 46), da vida na periferia (fragmento 47). Mas também esforçam-se, por meio de momentos que tratam da religiosidade (fragmentos 31, 36), da busca pelo amor (fragmento 42), dos sentimentos $(50,60)$, dos produtos culturais consumidos (fragmento 24, 32), para relevar e dar cor à humanidade presente no cotidiano dos sujeitos retratados, pertencentes às mais diversas classes econômicas.

Mantendo o foco no mínimo, na singularidade das histórias, $E E M C$ realiza a articulação da dimensão local e global, ou seja, explicita o modo como o Brasil está inserido na ordem global, e portanto está 
sujeito às transformações sócio-econômicas desta, que repercutem diretamente na vida das pessoas. Podemos afirmar que o vínculo dessa articulação, sem síntese, até agora lida em chave de continuidade com a tradição, com o experimentalismo formal constitui um tipo de ruptura com a mencionada tradição, e é responsável pelo caráter aberto da obra. A coadunação desses dois procedimentos modernos, o realismo e o experimentalismo formal, é um importante fator que possibilita as diversas leituras críticas presentes em Uma Cidade em Camadas: ensaios sobre o romance Eles eram muitos cavalos de Luiz Ruffato (2007). O amplo espectro de abordagens teóricas das leituras presentes neste livro chama a atenção e, em certa medida, serve para instaurar a questão, que discutiremos a seguir, acerca dos modos como o postulado de correspondência entre determinado momento histórico e a produção artística se aplica, distintamente, à teoria literária.

As articulações identificadas nessa breve apresentação da obra tentam mostrar a relação intrínseca e variável entre uma determinada concepção do fazer artístico e da sociedade, que não necessariamente encontra respaldo nas enunciadas intenções do autor. De qualquer modo, tais articulações realizadas pela crítica literária contribuem para a legitimação deste como autor e de seu texto como literatura.

Mais do que fazer uma análise crítica exaustiva do romance, nossa leitura objetiva estabelecer algumas das relações existentes entre a produção artística a prática da crítica literária e as implicações politicas desta. A seguir, nos debruçaremos sobre duas leituras que nos parecem significativas na abordagem do romance e, além disso, dão conta de um certo impasse político existente na teoria literária contemporânea e manifesto na seleção de critérios de sua valoração estética.

\section{Das leituras:}


Ao contrário do caráter auto-reflexivo de muitas das produções contemporâneas (a ficção tornou-se espaço de debate teórico e alguns dos escritores também são críticos profissionais), EEMC caracteriza-se, como dissemos, por ser uma obra aberta, detentora de um impulso em direção ao mundo. A escolha dos ensaios "Degradação e Acumulação: considerações sobre algumas obras de Luiz Ruffato" de Andrea Saad Hossne (2007) e "Fragmentos do Real e o Real dos fragmentos" de Karl Erik Schollhammer (2007) nos pareceu produtiva por colocar em tensão duas posições teóricas que também apontam, de modos distintos, como veremos, para uma intervenção na ordem das coisas do mundo.

A leitura de Hossne possui um pressuposto que pode ser identificado com o materialismo dialético, isto é, com uma concepção que postula a existência de uma homologia estrutural entre a realidade e as obras artísticas. Estas são entendidas, graças ao matiz adorniano da leitura, como objetos relativamente autônomos que possuem a capacidade de configurar e transfigurar esteticamente uma determinada realidade socioeconômica, e cuja forma, além de revelar algo sobre essa realidade, já é por si um elemento social e antagônico nela própria.

Em “Degradação e acumulação (...)", Hossne desenvolve e associa EEMC a três conceitos, são eles: "procedimento de acumulação", "romance arena" e "degradação urbana". Os dois primeiros conceitos estariam a serviço de substituir as ideias de montagem, sequencialidade e justaposição, as quais seriam insuficientes para explicar o procedimento constitutivo dessa obra. O efeito final de EEMC é obtido, de acordo com ela, devido à soma dos fragmentos, que podem ser lidos em qualquer ordem. Desse modo: “Acumular implica se não talvez, a precariedade em si mesma, decerto a sensação e a experiência de precário, que não se confunde, por sua vez, com o fragmento e o simplesmente inacabado" (2007, p. 36). O romance arena seria, portanto, aquele constituído pelos processos de acúmulo próprios à constituição da sociabilidade contemporânea, em que, porém, haveria 
uma abertura em direção a uma certa coletivização. Essa abertura e seus desdobramentos, contudo, não são desenvolvidos no texto.

A partir dessa obra, Hossne também problematiza a categoria "literatura urbana" proposta por alguns estudiosos, como Süssekind, que seria falha como caracterização da obra de Ruffato, da mesma forma que como categoria literária que dê conta do estatuto da produção literária contemporânea. Nesta, de acordo com a crítica, quando urbana, a cidade é tratada de modos heterogêneos, variados; vide exemplo de EEMC, em que o conceito mais aplicável para a temática seria o de "degradação urbana". Segundo Hossne, por meio das colagens, simultaneidades e da acumulação, é a própria degradação que se constrói diante do leitor" (p.18). Tal degradação formal teria como referente a degradação inerente ao fracasso do processo modernizador no Brasil, a relação entre o processo de urbanização e os projetos liberais e neo-liberais que o conduziram. A perversidade da ligação entre consumo, mercadoria e cidadania se plastifica na obra, a qual revela o que resultou da adoção de modelos europeus na construção de cidades, de um padrão de civilidade que, devido aos desajustes econômicos e culturais, no Brasil, resultou em concentração de renda, exclusões e segregações.

Essa análise muito se aproxima dos enunciados advindos de uma esquerda, de que fazem parte teóricos como Francisco de Oliveira e Roberto Schwarz (mencionados por ela), para os quais as perspectivas de uma efetiva transformação socioeconômica estrutural do Brasil são escassas - solicitando inclusive uma revisão dos conceitos marxistas à luz das inéditas configurações: a força de trabalho deslocada, a classe operária representativamente no poder (através do Partido dos Trabalhadores), representantes das grandes corporações na estrutura administrativa dos estados e pouco, ou nenhum, sistema social de resistência organizado. O fracasso de desenvolvimentismo e a degradação neoliberal não deixaram espaço para esperanças ou otimismos, liquidaram a utopia de uma revolução, já que nas configurações históricas e materiais atuais deixaram de existir 
condições para sua realização. O futuro próximo, assim como o diagnóstico do presente, nesta avaliação, catastrófico.

A leitura que Hossne faz da obra de Ruffato está sob a luz desse panorama desolador, recém descrito. De acordo com a crítica muito da temática ruffatiana "longe de constituir apenas fruto da elaboração imaginativa do autor, são quase transposições concretas de uma realidade predatória a que a escrita de Ruffato soube dar forma”. A utopia praticamente deixa de existir, citando Novaes, Hossne afirma:

Durante um período relativamente longo, o presente tinha sido melhor do que o passado, e o futuro melhor do que o presente. Mas, progressivamente, a idéia de um futuro de desenvolvimento individual vai se esfumando. A sociedade patina, não encontra saídas coletivas que restaurem o crescimento econômico acelerado e a mobilidade social ascendente. (2007, p. 24)

Nesse sentido, à medida que formaliza a relação das condições das nações periféricas à lógica transnacional do sistema capitalista, para Hossne, EEMC tem uma dimensão universal. Mesmo a problemática da definição do narrador está contida nesta perspectiva: Hossne identifica um ponto de vista narrativo, que seria a classe média pensante e desiludida com as possibilidades de transformação da sociedade.

O extrato marxista, de cunho adorniano, da análise de Hossne apresentada até aqui, nos permite afirmar uma concepção da crítica literária, assim como da literatura, como instrumento de crítica e oposição ao sistema capitalista. Ainda que a negatividade dos seus referenciais teóricos tenha atingido um ponto extremo e a validade deles tenha sido posta em cena, pelos próprios praticantes -- em entrevista recente, Schwarz comenta algo nesta direção:

Acontece que vivemos um momento em que a idéia de sociedade como algo circunscrito, com destino próprio, está posta em questão, para não dizer em decomposição. [...] E no campo das obras, com a entrada maciça do mercado e da mídia na cultura, é voz corrente que a idéia de arte mudou, e é possivel que o padrão de exigência do período anterior tenha sido abandonado. Talvez os 
pressupostos da crítica dialética estejam desaparecendo. (AUERBACH, 2002)

- ao se fazer o elogio a $E E M C$ reforça-se a existência e distinção de alguns objetos potencialmente críticos nos tempos pósmodernos. A crítica, o autor, a literatura, a obra e uma determinada concepção do atual momento histórico são legitimados.

Já Schollhammer propõe uma reflexão que se foque na forma experimental da obra, mostrando como esta "mantém não só o compromisso com a realidade, mas procura formas de realização literária ou de presentificação não-representativa dessa mesma realidade". Seu esforço inicial, desde uma matriz teórica que poderíamos associar à desconstrução, é o de delimitar a diferença entre o processo de representação de Ruffato e o realismo clássico:

a escrita de Ruffato revela a dimensão invisivel do visto, aquilo que mortifica o olhar contemplativo e exterior ao cenário urbano e suburbano, incorporando esse olhar no próprio cenário em uma certa inversão com clara dimensão ética. (SCHOLLHAMMER, 2007, p.70)

O realismo de Ruffato seria, para Schollhammer, um realismo particular: performativo e indicial. Ou seja, na medida em que a inclusão de textos extra-literários, como a transcrição dos santinhos de Sto. Expedito, cardápios, anúncios de emprego, é lida por esse crítico como um claro processo de bricolagem textual, signos da cidade incluídos entre os signos da ficção, esses elementos teriam como função "arraigar ou indexar o texto no real", isto é, desnaturalizar a referencialidade do realismo (a escrita da própria cidade inserida no contexto ficcional equivaleria a um objeto real incluido numa obra de arte ou como uma foto real inserida em uma narrativa ficcional). Esse procedimento também marcaria certa distância das técnicas utilizadas pelas vanguardas.

Desse modo, numa oposição à leitura de Hossne, a obra estaria cheia de signos que "só demandam o reconhecimento de sua evidência inegável, não adiante interpretar e procurar um sentido profundo escondido (...) O que têm a mostrar não está fora deles 
mesmos, apenas referem-se a sua própria existência” (2007, p.72). Isso implica uma eliminação da diferença entre forma e conteúdo, efetuada com a adoção do recurso poético dentro da prosa, que resulta na ambiguidade entre "expressão da realidade e realidade da expressão". Em convergência com a análise de Hossne, Schollhammer define o caráter fragmentário do romance como alegoria da impossibilidade de integração orgânica, do que há de inacabado e irreconciliável na realidade urbana contemporânea, neste caso, porém, pensada em termos não necessariamente vinculados ao discurso tradicional de interpretação histórico-sociológica brasileira.

A estrutura da obra que é lida por Hossne na chave do "acúmulo" apresenta-se, segundo o crítico, como uma estrutura rizomática, sem sequencialidade causal, nem centro. As diversas histórias e personagens formariam, de acordo com ele, uma clara polifonia de linguagens intraduziveis e incomunicáveis entre si, mas que, no momento performativo (que possui uma temporalidade própria imposta pela escrita) da recepção pelo leitor, criaria, assim como sugere Hossne, um "espaço de conexão emocional coletiva, cujos desdobramentos também não são explicitados".

O acento que Schollhammer coloca no procedimento formal de EEMC evidencia, para além da descrição realista, aquilo que não é visto no cotidiano de uma grande cidade, os medos, as angústias, o sofrimento e também a presença dos sonhos e das expectativas dos moradores da cidade de São Paulo. A reflexão derridiana, presente explicitamente nesta leitura, realiza questionamentos acerca do outro e vislumbra a possibilidade de que algo seja construído a partir de dissensos, pois estes seriam irreparáveis à medida que a lingua falada por esses sujeitos é diferente e nesta diferença há sempre uma tentativa, violenta, de imposição sobre o outro.

Nas leituras filtradas pelo aparato teórico da desconstrução é comum conferir-se importância à emergência de subjetividades e minorias, bem como, numa análise socioeconômica, as chamadas micro-politicas serem vistas como potencialmente significativas. 
Hossne, ao contrário, vê com descrédito tais caracterizações, já que elas não configurariam uma alteração na estrutura do sistema, e, inversamente às suas pretensões, ao despedaçarem a cidadania (uma cidadania cultural, outra racial, outra de gênero, outra ecológica), acabariam por ratificá-lo ainda mais; pois adotariam uma visão que associa cidadania e nichos do mercado quando estas questões deveriam ser resolvidas por politicas públicas ou outras intervenções do estado.

No pensamento derridiano, que ecoa em Schollhammer, a revolução não aparece como fim último capaz de instaurar um novo sistema socioeconômico: tem-se como plano de ação uma espécie de reformismo radical, baseado na ideia de responsabilidade infinita e vinculado à premissa, tão mal compreendida, de que não existem acontecimentos fora do texto. Esse pressuposto explica-se a partir de uma concepção filosófica (a crítica à metafisica da presença) para qual o processo de determinação de sentido de um acontecimento é sempre dado a posteriori através de uma prática discursiva - e por isso teríamos responsabilidade infinita pelos enunciados que produzimos ou reinscrevemos num presente. Sendo assim, não há fato que não possa ter seu sentido reescrito, re-trabalhado ou mesmo apagado. A cidade, e seus problemas, seria assim produto desses textos, que devem ser entendidos como algo diferente de simbolos gráficos numa folha de papel. E talvez, aqui, resida uma oposição fundamental, mas discutivel, entre as análises comparadas, para Hossne (2007): "a cidade é, em grande parte, reprodução da força de trabalho".

Desse modo, para Derrida não é possivel uma transformação social que não passe pela linguagem:

A Desconstrução radical, conseqüente com relação a ela mesma, não quer permanecer fechada em discursos puramente especulativos, teóricos e acadêmicos, mas pretende ter conseqüências, mudar as coisas e intervir de modo eficiente e responsável (embora sempre mediado, claro) não apenas na profissão mas naquilo que chamamos a cidade, a pólis e, mais geralmente, o mundo (DERRIDA, 2007, p. 14)

Daí a necessidade de Schollhammer colocar a ressalva: 
Esse esforço de incluir a realidade na escrita não deve ser confundido com documentarismo, pelo contrário, não se trata apenas de trazer a realidade para dentro da narrativa, senão de levar a poesia à vida, reencantá-la, comprometer a escrita ao desafio do índice e fazer dela um meio de intervenção sobre aquilo que encena ficcionalmente. (DERRIDA, 2007, p. 14)

A atenção dos desconstrucionistas para com os textos, que é vista por alguns como um tipo de esteticismo, apoia-se nessa premissa, que também permite Schollhammer acreditar que EEMC politiza a estética e esteticiza a política ao por em cena formalmente uma realidade que não depende de interpretação ideológica, já que é visivel por si mesma. Neste caso, ele está se referindo à mencionada presença estética dos signos e vozes que normalmente não ocupam o espaço literário. Esse argumento é, sem embargo, questionável, se considerarmos a impossibilidade de uma apreensão da realidade sem mediações, de várias ordens, e ao mesmo tempo interrogarmos sobre o quanto de fato há, e de que modo, a presença dessas vozes e signos no texto.

A não existência de uma única verdade é, como se sabe, imperativa nas preocupações do pós-estruturalismo, que, entretanto, contrariando as leituras que convencionalmente o enquadram num tipo de relativismo, tem como horizonte transcendental - no caso de Derrida - a justiça. Esta existiria como um ponto de excesso no estado de direito. Ou seja, o direito e a justiça seriam coisas separadas e a instauração tanto de um quanto do outro exige a força. A confiança no Estado como agenciador dessa justiça pode ser perigosa e por isso reitera-se o potencial da linguagem: "O que se deve pensar é, pois, esse exercício da força na própria linguagem, no mais íntimo de sua essência, como no movimento pelo qual ela se desarmaria absolutamente por si mesma" (2007, p.17)

O impasse a que estas leituras, quando contrapostas, parecem levar é bem definido pelas acusações mútuas que costumam partir de seus praticantes e se resume na dicotomia entre negatividade 
conformista versus otimismo acrítico. Nossos esforços vão na direção de evitar a simplificação e ignorância imbricada em tal binarismo.

\section{Considerações finais}

As leituras apresentadas têm como referenciais teóricos diferentes tradições do pensamento: a francesa e a alemã, mediadas por distintas compreensões da sociedade brasileira. A despeito daquilo que permanece irredutivel e inconciliável entre os posicionamentos de Hossne e Schollhammer - a primeira posição é teleológica enquanto a segunda busca o rompimento com teleologias -, acreditamos na relação de suplementariedade, ou, se quisermos usar o termo da tradição alemã, dialética entre as duas leituras ${ }^{3}$. Ademais, ambas leituras enfatizam o trabalho formal do romance e corroboram para a defesa da autonomia do objeto literário - mesmo que o segundo aponte para uma direção em que esta é passivel de ser problematizada - e neste gesto demarcam distância de parte do ideário pós-moderno que questiona tal autonomia. 4

O modo como o romance EEMC apropria-se dos recursos técnicos pertencentes à modernidade e formaliza uma determinada matéria, passando assim a ser a própria matéria, nos parece significativo dentro da produção literária contemporânea, na medida que contrapõe-se aos mecanismos dicotômicos e totalizantes do pensamento e exige da crítica uma constante atenção para com as categorias da teoria literária. A obra situa-se no momento histórico de

3 Os conceitos de suplementariedade e dialética apesar de serem distintos apresentam um alto grau de similitude. O suplemento é o elemento que permite a totalização da estrutura e é ao mesmo tempo um excesso em relação a ela. $\mathrm{O}$ suplemento deve ser acrescentado para que a origem se legitime enquanto tal, ao mesmo tempo ele a revela como insuficiente. Do mesmo modo a dialética, evidencia que no interior de um conceito já há algo que motiva sua superação, que ao negá-lo está também afirmando-o.

4 Tornou-se lugar comum associar o pós-modernismo ao pós-estruturalismo. Contudo, é necessário que de delimitem as fronteiras entre essas duas correntes. O ensaio "Mapeando o pós-moderno" de Andreas Hyussen fornece contribuições produtivas para essa tarefa. HUYSSEN, Andreas. "Mapeando o pós-modernismo". In: Pós-modernismo e política. Hollanda, Heloisa Buarque [org]. Rio de Janeiro: Rocco, 1991. 
cruzamento entre diversos projetos políticos e parece dar conta da complexidade deste período.

A relação obliqua que a literatura estabelece com a noção de verdade é de grande valia para nosso argumento. Discorremos sobre o modo como EEMC se oferece às mais diversas leituras, que podem ser justificadas e bem fundamentadas na obra, mas que comportam diferentes concepções de mundo e do objeto artístico. Nesta dinâmica, fica claro que a relação da teoria literária com a noção de verdade é outra. Parece-nos que a reflexão crítica pode ganhar ao ser pensada em relação com os diversos posicionamentos teóricos. Tal movimento não tem pretensões conciliatórias ou homogeneizantes, mas concebe a possibilidade de co-ocorrência, no lugar da concorrência em moldes partidários, desses posicionamentos como produtiva. Ao colocar duas leituras em confronto tentamos explicitar a vinculação entre valores estéticos e projetos políticos, que sempre possuem implicações e pressuposições significativas.

Esse exercício nos parece altamente crítico na direção - e aqui explicitamos a dimensão politica da nossa leitura, que também utilizou-se de determinados critérios de valoração estética - de uma prática democrática, em nossa concepção, ainda por vir. Prática esta que envolve a relação com os textos literários e a crítica e que não assegura consensos, já que a democracia por vir, não nos parece algo estático ou monocromático; pelo contrário, a instabilidade e o movimento seriam seus principais constituintes. Uma democracia que permita a crítica de seus valores sem com isso se desconstruir, demonstrando assim não sua fragilidade, mas sua vitalidade. Uma prática democrática que deixa o futuro sempre em aberto, já que ela pressupõe instituições reformáveis, modificáveis, aperfeiçoáveis e até mesmo mudanças estruturais. 


\section{Referências Bibliográficas}

AUERBACH, Erich. "Na mansão de la Mole". In: Mimesis: a representação da realidade na literatura ocidental. São Paulo: Perspectiva, 1971.

DERRIDA, Jacques. Força de Lei: o fundamento místico da autoridade. MOISÉS, Leyla Perrone [trad]. São Paulo: WMF Martins Fontes, 2007. HARISON, Marguerite Itamar [org.]. Uma cidade em Camadas: ensaios sobre o romance Eles eram muitos cavalos de Luiz Ruffato. São Paulo: Editora Horizonte, 2007.

OLIVEIRA, Francisco de. E. RIZEK, Libeli Saliba [orgs.]. A era da indeterminação. São Paulo: Boitempo, 2007.

RUFFATO, Luiz. Eles eram muitos cavalos. São Paulo: Boitempo, 2001. .Entrevista. Disponivel em http://www.geocities.com/SoHo/Lofts/1418/ruffato.htm. Acesso em 07/07/09. SCHWARZ, Roberto. "Fim de século". In: Sequências brasileiras. São Paulo: Companhia das Letras, 1999.

Entrevista. Literatura e sociedade/Departamento de teoria literária e literatura comparada/ Faculdade de Filosofia Letras e Ciências Humanas/Universidade de São de Paulo-(2002). São Paulo: USP/FFLCH/DTLLC, 2002.

SÜSSEKIND, Flora. Desterritorialização e forma literária. Literatura brasileira contemporânea e experiência urbana. Literatura e sociedade Número 8, São Paulo, 2005. 